\section{P2-S4.07 UNSAFE CASUAL TRAVEL SEX WITH DISCORDANT AND CONCORDANT PARTNERS IS COMMON AMONG VISITORS OF A LARGE STI OUTPATIENT CLINIC IN AMSTERDAM; RISK FOR INTERNATIONAL SPREAD OF STI}

doi:10.1136/sextrans-2011-050108.339

${ }^{1} \mathrm{~A}$ Urbanus, ${ }^{1} \mathrm{~T}$ Heijman, ${ }^{2} \mathrm{G}$ Sonder, ${ }^{2} \mathrm{~A}$ van den Hoek. ${ }^{1}$ Amsterdam Public Health Service, Amsterdam, Netherlands; ${ }^{2}$ Center for Infection and Immunology Amsterdam, CINIMA, Academic Medical Center, AMC, Netherlands

Background Travelling has always been an important factor in the spread of STI. In the last decades international travelling has become very popular and therefore the risk for spreading STI internationally has become higher. Here we examine determinants of casual travel sex among visitors of a large STI clinic in the Netherlands. With these results specific advice about safe casual travel sex might be given.

Methods During three waves of the bi-annual anonymous survey (mid 2008-mid 2009), 2971 attendees of the STI clinic Amsterdam, were interviewed about risk factors for blood-borne and sexually transmitted infections and about casual travel sex in the past 6 months. Determinants of casual travel sex were analysed using logistic regression. Analyses were done combined and separately for participants with Western, Surinam, and other ethnicity.

Results In total 949/2971 (32\%) participants had casual travel sex in the 6 months preceding the visit to our STI clinic. Of these participants 265 (28\%) were women, 299 (32\%) heterosexual men and 385 (41\%) MSM. Participants who had casual travel sex were more often heterosexual men (OR 1.66, 95\% CI 1.37 to 2.01) or MSM (OR 3.03, $95 \%$ CI 2.50 to 3.68 ), were older (median 31 vs 27 ; $<<0.0001$ ), had more often a history of STI (OR $1.66,95 \%$ CI 1.42 to 1.94 ) and had a higher number of life time sexual partners (median 26 vs 13; $p<0.0001)$. Participants who had unsafe travel sex were younger (mean 29 vs 33; $\mathrm{p}<0.001$ ) and had less often a STI in the past (OR $1.41,95 \%$ CI 1.08 to 1.82). In particular Western participants reported a high number of casual travel sex with discordant ethnic partners. In addition they reported more frequently unsafe sex with both discordant and concordant ethnic partners (see table). Around $60 \%$ of Western women, heterosexual men and MSM who had casual travel sex, had sex with a discordant ethnic partner. However, Western MSM were more likely to use a condom during casual travel sex (OR 2.39, 95\% CI 1.45 to 3.92) than heterosexual men and women see Abstract P2-S4.07 Table 1

Conclusion Casual travel sex is very common among visitors of our STI clinic compared with the ca. $5 \%$ reported among visitors of a travel clinic, in particular among visitors who are older, with a high number of lifetime sex partners and with previous STI. These findings give insight in the risk of the international spread of STI and may be of help in providing specific pre-travel advice on safe sex abroad.

Abstract P2-S4.07 Table 1 Number of participants who have casual travel sex per ethnicity group

\begin{tabular}{lrrrr}
\hline & $\begin{array}{l}\text { Casual travel } \\
\text { sex }\end{array}$ & $\begin{array}{l}\text { With discordant } \\
\text { ethnicity group }\end{array}$ & $\begin{array}{l}\text { Unsafe sex with } \\
\text { discordant ethnicity } \\
\text { group }\end{array}$ & $\begin{array}{l}\text { Unsafe sex with } \\
\text { concordant } \\
\text { ethnicity group }\end{array}$ \\
\hline Participant & & & & \\
Western $^{*}$ & $647 / 1931(33.5 \%)$ & $384 / 647(59.0 \%)$ & $201 / 380(52.9 \%) \dagger$ & $160 / 263(60.8 \%)$ \\
Suriname & $70 / 358(19.6 \%)$ & $35 / 70(50.0 \%)$ & $13 / 35(37.1 \%)$ & $18 / 34(52.9 \%) \dagger$ \\
Other & $232 / 682(34.0 \%)$ & $93 / 232(40.1 \%)$ & $48 / 93(51.6 \%)$ & $73 / 136(53.7 \%) \dagger$ \\
\hline
\end{tabular}

*Dutch included.

†Missings excluded.
P2-S4.08 PATTERNS AND CORRELATES OF CONDOM USE AT LAST SEX EPISODE IN A POPULATION PRESENTING FOR VOLUNTARY HIV COUNSELLING AND TESTING IN SOWETO, JOHANNESBURG

doi:10.1136/sextrans-2011-050108.340

${ }^{1} \mathrm{~T}$ Nshimiyimana, ${ }^{1} \mathrm{E}$ Thandekile, ${ }^{2} \mathrm{~K}$ Katz, ${ }^{1} \mathrm{~N}$ Martinson, ${ }^{1} \mathrm{G}$ Gray, ${ }^{1} \mathrm{G}$ de Bruyn. ${ }^{1}$ Perinatal HIV Research Unit, Johannesburg, South Africa; ${ }^{2}$ Harvard Medical School, USA

Background Promotion of condom use remains an important public health intervention to prevent HIV transmission and acquisition. Routine data from voluntary counselling and testing (VCT) can inform evaluation of prevention efforts that emphasise condom use. This study uses a Johannesburg township VCT data to characterise the correlates of condom use at the sexual episode that preceded VCT visit.

Methods This retrospective analysis uses a service level data on 2829 individuals seeking VCT at a Soweto-based testing center between 2008 and 2010. Multivariate models were used to compare the correlates of condom use with clients' HIV-1 serostatus.

Results Women were 1800 (63.6\%) with a mean age of 32 while men were 1029 (36.4\%) with a mean age of 35. Out of 1,862 clients reporting sexual intercourse within the month that preceded VCT visit, $27.8 \%$ were HIV-1 infected. Among 1,916 HIV-1 seronegative clients, $51.8 \%$ reported not using condom at last sexual episode compared to $44 \%$ among 911 clients in the HIV-1 seropositive subgroup. HIV-1 seropositive clients reporting not having a sex partner but who described their most recent sexual episode as casual were less likely to have used a condom during that sex act compared to those who reported having their last sex with their regular partners (Adjusted Odd Ratios [AOR], 0.4; 95\% CI, 0.2 to 0.6). This difference was not observed in the HIV-1 seronegative subset. In the HIV-1 seropositive subgroup, those reporting previous exposure to VCT were more likely to have used a condom during the sex episode that preceded their VCT visit compared to those reporting it was their first encounter with VCT (AOR, 2.6; 95\% CI 1.6 to 4.3). However, the effect of previous exposure to VCT on condom use was not significant in the HIV-1 seronegative subset. For both the HIV-1 seronegative and seropositive subsets, condom use likelihood was higher among men compared to women (AOR, 1.6; 95\% CI 1.2 to 2.0 and AOR 1.7 ; $95 \%$ CI 1.1 to 2.7 ), respectively.

Conclusion The findings underline a need for distinguishing HIV risk reduction counselling targeted at the HIV-1 infected from those aimed at the HIV-1 uninfected, especially in Soweto context.

\section{P2-S4.09 ABSTRACT WITHDRAWN}

\section{P2-S4.10 CHARACTERISTICS ASSOCIATED WITH CONDOM BREAKAGE/SLIPPAGE OR PARTIAL USE DURING VAGINAL SEX WITH MAIN AND NON-MAIN PARTNERS: FINDINGS FROM THE SAFE CITY PROJECT STUDY}

doi:10.1136/sextrans-2011-050108.342

${ }^{1} \mathrm{~L}$ D'Anna, ${ }^{2} \mathrm{~A}$ Margolis, ${ }^{2} \mathrm{~L}$ Warner, ${ }^{1} \mathrm{O}$ Korosteleva, ${ }^{3} \mathrm{~L}$ O'Donnell, ${ }^{4} \mathrm{C}$ Rietmeijer, ${ }^{5} \mathrm{~J}$ Klausner, ${ }^{1} \mathrm{C}$ K Malotte. ${ }^{1}$ California State University, Long Beach, Long Beach, USA; ${ }^{2}$ Centers for Disease Control and Prevention, Atlanta, USA; ${ }^{3}$ Education Development Center, Boston, USA; ${ }^{4}$ Denver Public Health, Denver, USA; ${ }^{5}$ University of California, San Francisco, USA

Background Condom use problems including breakage, slippage, or partial use (delayed application or early removal) jeopardise condom effectiveness. Our research aims were to: 1) assess the prevalence of condom use problems among urban US STD clinic users; 2) identify participant and partner characteristics and Behaviours associated with condom use problems; and 3) examine how these 